\title{
Educational achievement and fracture risk: response to Clark and Tobias
}

\author{
S. L. Brennan • J. A. Pasco • D. M. Urquhart • \\ B. Oldenburg • F. Hanna • A. E. Wluka
}

Received: 19 October 2009 / Accepted: 27 October 2009 /Published online: 9 December 2009

(C) International Osteoporosis Foundation and National Osteoporosis Foundation 2009

\section{Dear Editors,}

We thank Drs Clark and Tobias [1] for their comment regarding our systematic review, which examined the role of socioeconomic status (SES) of the individual adult aged $>55$ years and their risk of osteoporotic fracture [2]. The strict eligibility criteria of our review meant that studies that had examined the role of parents' SES upon bone mass acquisition by their offspring did not fulfil the inclusion criteria.

The findings of this review were based upon the data provided by 11 eligible studies ranked as high quality. Three of the studies ranked as high quality had examined education as a prime predictor [3-5]. Of these, only one was a cohort study from which causality could be inferred [3]; however, it did not adjust for height and weight. Further, of the two cross-sectional studies that assessed education and were deemed as high quality, only one had accounted for body mass index (BMI) in the final model [5]. Thus, we confirm that not all the reviewed studies had accounted for weight or height within the final model, although they had adjusted for various combinations of other risk factors for low bone mass, including age, gender, smoking, physical activity, medications, and prior fracture.

\footnotetext{
S. L. Brennan · D. M. Urquhart $\cdot$ B. Oldenburg $\cdot$ F. Hanna $\cdot$

A. E. Wluka $(\square)$

Department of Epidemiology and Preventive Medicine,

Monash University,

Melbourne, Australia

e-mail: Anita.Wluka@med.monash.edu.au
}

\section{J. A. Pasco}

Department of Clinical and Biomedical Sciences: Barwon Health,

The University of Melbourne,

Geelong, Australia
The additional explanation for the conflicting association between educational attainment and fracture suggested by Clark and Tobias [6] may be plausible. However, since the lead time between bone mass of children and osteoporotic fracture in later life is considerable, the strength of this association may be attenuated by many other influences during the intervening years, including co-morbidities, medication use, smoking, alcohol, diet, physical activity, and the occupational environment. Thus, the complex interrelationship between bone area and bone mass in adulthood in relation to SES may differ from that in childhood. However, that being said, the alternative explanation provided by Clark and Tobias suggests a conceivable explanation and offers an additional and very interesting area of further enquiry.

\section{References}

1. Clark E, Tobias J (2009) Educational achievement and fracture risk. Osteoporos Int. doi:10.1007/s00198-009-1115-7

2. Brennan SL, Pasco JA, Urquhart DM, Oldenburg B, Hanna F, Wluka AE (2009) The association between socioeconomic status and osteoporotic fracture in population-based adults: a systematic review. Osteoporos Int 20:1487-1497

3. Wilson R, Chase GA, Chrischilles EA, Wallace RB (2006) Hip fracture risk among community-dwelling elderly people in the United States: a prospective study of physical, cognitive and socioeconomic indicators. Am J Pub Health 96:1210-1218

4. Vestergaard P, Rejnmark L, Mosekilde L (2006) Socioeconomic aspects of fractures within universal public healthcare: a nationwide case-control study from Denmark. Scand J Pub Health 34:371-377

5. Farahmand BY, Persson PG, Michaelsson K, Baron JA, Parker MG, Ljunghall S (2000) Socioeconomic status, marital status and hip fracture risk: a population-based case-control study. Osteoporos Int 11:803-808

6. Clark EM, Ness A, Tobias JH, ALSPAC Study Team (2005) Social position affects bone mass in childhood through opposing actions on height and weight. J Bone Miner Res 20:2082-2089 